\title{
Glossy15, an APETALA2-like gene from maize that regulates leaf epidermal cell identity
}

\author{
Stephen P. Moose $\mathrm{e}^{1,2,4}$ and Paul H. Sisco ${ }^{2,3,5}$ \\ Departments of ${ }^{1}$ Genetics and ${ }^{2}$ Crop Science and ${ }^{3}$ United States Department of Agriculture/Agricultural Research Service, \\ North Carolina State University, Raleigh, North Carolina 27695-7620 USA
}

\begin{abstract}
Vegetative development in many plants progresses through distinct juvenile and adult phases. In maize, the transition from juvenile to adult shoot development affects a variety of leaf epidermal cell traits. These include epicuticular waxes, leaf hairs, and cell wall characteristics. Previous genetic and phenotypic analyses have shown that the maize Glossy15 (G115) gene is required for the expression of juvenile epidermal traits after leaf 2. We report here the molecular cloning of the Gl15 gene using a defective Suppressor-Mutator (dSpm) element insertion as a transposon-tag. Consistent with the gl15 mutant phenotype, the pattern of Gl15 mRNA expression was correlated with a juvenile leaf epidermal cell identity and was regulated by upstream factors such as Corngrass1. The Gl15 gene encodes a putative transcription factor with significant sequence similarity to the Arabidopsis regulatory genes APETALA2 and AINTEGUMENTA, which act primarily to regulate floral organ identity and ovule development. This finding expands the known functions of APETALA2-related genes to include the control of both vegetative and reproductive lateral organ identity and provides molecular support for the hypothesis that leaves and floral organs are related structures derived from a common growth plan.
\end{abstract}

[Key Words: Leaf development; organ identity; heteroblasty; phase change; transposon-tagging]

Received August 12, 1996; revised version accepted October 16, 1996.

Vegetative shoot development in many plants is characterized by the production of both juvenile and adult leaves, or heteroblasty (Goebel 1900; Allsopp 1967). The basal juvenile and upper adult leaves are often sufficiently distinct with respect to their shape, anatomy, and physiological characteristics that they may be considered to have different identities in the same sense that floral organs such as sepals and petals have different identities (Poethig 1990; Smith and Hake 1992). The determination of juvenile and adult leaf characteristics is subject to both genetic and hormonal influences that act on the shoot apical meristem and developing leaf primordia (for review, see Lawson and Poethig 1995). Currently, little is known about the molecular mechanisms that regulate the transition from juvenile to adult shoot development.

The juvenile and adult leaves of maize differ for a large set of epidermal traits (Poethig 1990). Some of these are illustrated in Figure 1, and include the formation of specialized cell types such as leaf hairs and bulliform cells, the ultrastructure and biochemical composition of epicuticular waxes, epidermal cell morphology, and cell

${ }^{4}$ Current address: Department of Biology, University of California-San Diego, La Jolla, CA 92093-0116.

${ }^{5}$ Corresponding author. wall reactions with histochemical stains. The epidermis of the basal 5 or 6 juvenile leaves consists largely of a single cell type that has acidic cell walls and produces juvenile waxes. Beginning with leaf 6 there is a transition to the adult leaf form such that beyond node 8 , leaves are exclusively adult. The adult leaf epidermis develops a number of differentiated cell types. Bulliform cells and their associated leaf hairs occur in longitudinal files over leaf veins and are separated by cells that lack juvenile waxes and have invaginated, neutral cell walls.

A number of maize mutations regulate the spatial/ temporal expression of juvenile and adult leaf epidermal traits during shoot development. The dominant, gain-offunction Corngrass1 (Cg1), Teopod1 (Tp1), and Teopod2 $(T p 2)$ mutations extend the expression of all juvenile vegetative traits (axillary tillers, adventitious roots, juvenile leaves), leading to an increase in the number of juvenile leaves or leaves with both juvenile and adult characteristics (Galinat 1966; Poethig 1988). The maize $d$ warf mutants, which affect gibberellic acid biosynthesis and have a short andromonecious phenotype, also produce more juvenile leaves and interact synergistically with the Tp mutations (Evans and Poethig 1995). In contrast to the pleiotropic effects on vegetative and reproductive growth associated with each of these mutations, recessive glossy15 (g115) mutations condition the re- 


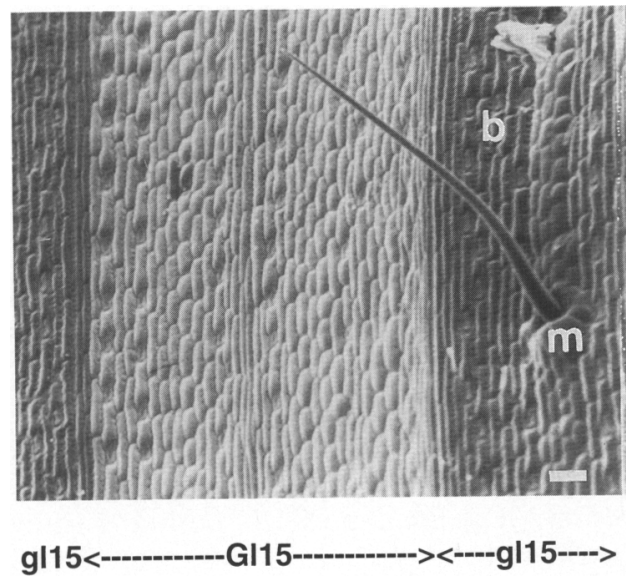

Figure 1. The glossy15-mutable phenotype. A scanning electron micrograph of the adaxial surface of leaf 4 from an Spmactive, homozygous g115-mutable plant. A revertant sector (center), in which Gl15 activity has been restored by the transposition of the $d S p m$ element from the g115-m1 allele, is flanked by g115 mutant tissue, where the $d S p m$ insertion disrupts gene function. The juvenile epidermal cells within the Gl15-active sector produce a visible layer of crystalline waxes and possess wavy lateral cell walls. In the adjacent g115 mutant tissues, juvenile cells are replaced by adult epidermal cells with invaginated walls, bulliform cells (b), and leaf macrohairs (m). Bar, $100 \mu \mathrm{m}$ placement of juvenile with adult leaf epidermal traits beginning with the third leaf but do not affect any other phenotypes associated with the transition from juvenile to adult vegetative growth (Evans et al. 1994; Moose and Sisco 1994). Additionally, genetic analysis has demonstrated that gl15 acts downstream of the $C g 1, T p 1, T p 2$, dwarf1, and dwarf3 mutations (Moose and Sisco 1994; Evans and Poethig 1995). These observations suggest that G115 acts specifically to promote a juvenile leaf epidermal cell identity.

We have characterized previously the phenotypic effects associated with a transposon-induced mutable allele of $g 115$ (g115-m1) caused by the insertion of a defective Suppressor-Mutator (dSpm) element (Moose and Sisco 1994). Gl15 acts in a cell-autonomous fashion and is required for the coordinate activation of juvenile and suppression of adult traits in the leaf epidermis (Fig. 1). Here we report the molecular isolation of the Gl15 gene using the $d S p m$ insertion as a transposon-tag. Gl15 mRNA expression is correlated with a juvenile leaf identity beyond leaf 2 . The predicted G115 gene product encodes a member of the AP2-domain family, based on its significant similarities to the two AP2 domains from the Arabidopsis regulatory genes APETALA2 (AP2; Jofuku et al. 1994) and AINTEGUMENTA (ANT; Elliott et al. 1996; Klucher et al. 1996). Sequences related specifically to G115 are also present in other monocot and dicot plant species. The similarities between Gl15 and genes regulating floral organ identity $(A P 2)$ and ovule development $(A P 2, A N T)$ indicate that $A P 2$-related genes participate
A

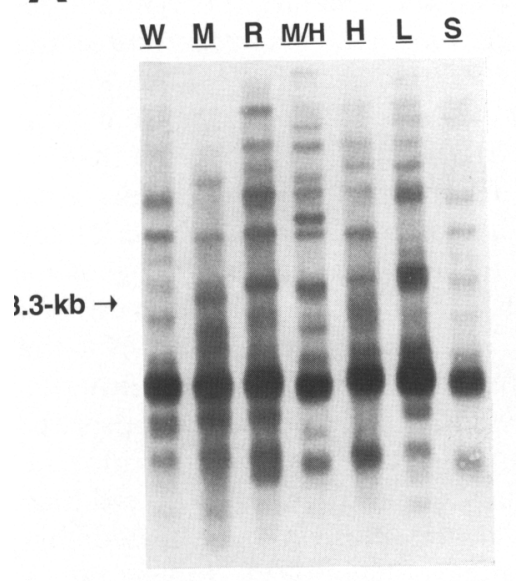

3.3-kb $\rightarrow$

$\underline{\text { W }} \underline{M} \underline{\mathrm{R}} \underline{\mathrm{M} / \mathrm{H}} \underline{\mathrm{H}} \underline{\mathrm{L}} \underline{\mathrm{S}}$

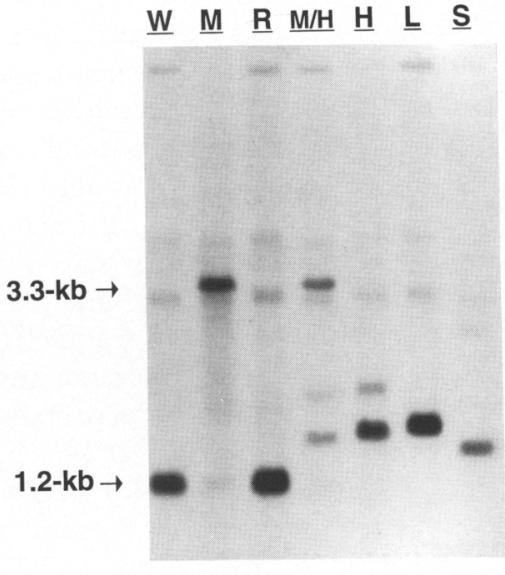

B

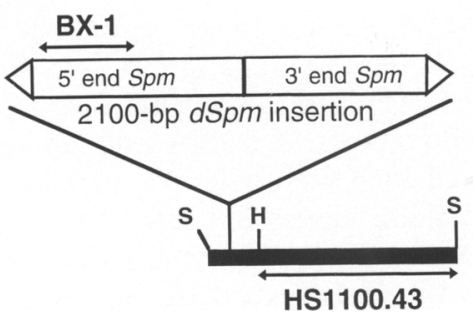

Figure 2. Molecular cloning of Gl15. (A) DNA gel blot of SstI-digested genomic DNAs from plants carrying different alleles of the G115 locus probed with the BX-1 fragment of the Spm transposon. Alleles are designated as follows: (W) normal G115-W64A allele from the inbred W64A; (M) g115-m1::dSpm; (R) germinal revertant derivative obtained from g115-m1. Three known g115Ref alleles are designated: (H) Hayes; (L) Lambert; and (S) Sprague (Moose and Sisco 1994). The $\mathrm{M} / \mathrm{H}$ lane contained DNA from a sibling of the germinal revertant plant. This sibling was heterozygous for $g 115-\mathrm{m} 1$ and $g 115-H$ and showed a g115-mutable phenotype. A 3.3-kb band in plants carrying the gl15- $\mathrm{m} 1$ allele and absent from revertant derivatives of $g 115-\mathrm{m} 1$ is indicated by the arrow. $(B)$ Restriction map of the cloned $3.3-\mathrm{kb}$ SstI fragment from the $g 115-\mathrm{m} 1$ allele. The $2.1-\mathrm{kb}$ $d S p m$ element insertion and the relative position of the BX-1 fragment used as a hybridization probe are shown. The region spanned by the HS1100.43 probe flanking the $d S p m$ insertion is underlined. (C) The blot in $A$ was stripped and rehybridized with the HS1100.43 probe derived from the cloned $3.3-\mathrm{kb}$ fragment in $B$. The $3.3-\mathrm{kb}$ fragment from the $g 115-\mathrm{m} 1$ allele and the $1.2-\mathrm{kb}$ fragment from the G115-W64A and either somatic or germinal revertant alleles are indicated. Distinct RFLPs relative to wild type were also observed among the three g115-Ref alleles. 
A

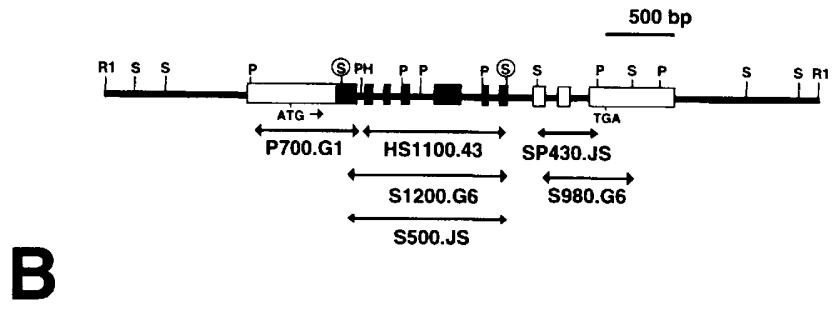

g/15-Hayes

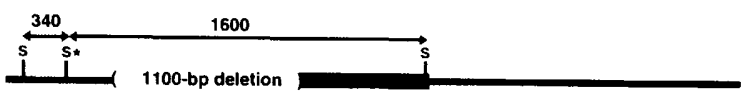

gl15-Lambert
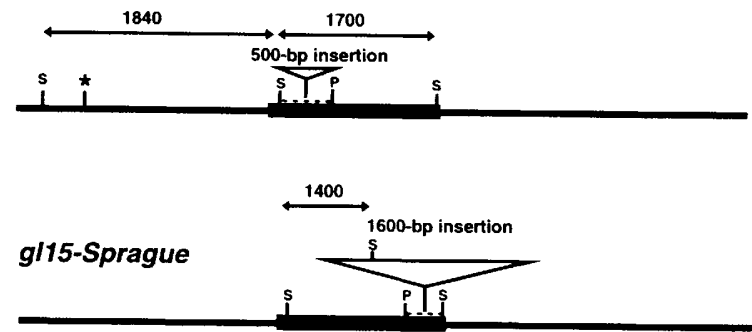

Figure 3. Structure of wild-type and mutant Gl15 alleles. $(A \mid$ Structure of the $6.0-\mathrm{kb} E c o$ RI restriction fragment from the Gl15-W64A allele. EcoRI (RI), SstI (S), and PstI (P) restriction sites are indicated, the two $S s t \mathrm{I}$ sites delimiting the $3.3-\mathrm{kb}$ fragment initially isolated from the g115-m1::dSpm allele are circled. The black box represents the putative nuclear localization signal and two AP2 domains conserved between G115 and AP2. The positions of the putative translational start (ATG) and stop (TAG) codons are labeled. The regions represented by the genomic (HS1100.43, P700.G1, S1200.G6, S980.G6) and cDNA (S500.JS, SP430.JS) restriction fragments used as hybridization probes are underlined. $(B)$ Restriction maps of the g115-Ref alleles for the region represented by the $6.0-\mathrm{kb} E c o$ RI fragment from G115-W64A, derived from restriction and hybridization analysis of genomic DNA using the P700.G1, S1200.G6, and S980.G6 restriction fragments as probes. Only relevant SstI (S) and PstI $(\mathrm{P})$ restriction sites are labeled for reference. For each map, the black box indicates the AP2 domain region conserved between $G 115$ and $A P 2$. An asterisk represents the missing SstI site in the $g 115-L$ allele. This same site appears to be methyated partially in the $g 115-H$ allele, denoted by an S. The approximate positions and sizes of the lesions in the g115-Ref mutant alleles relative to the G115-W64A allele are indicated by triangles (insertion) or parentheses (deletion). Dashed lines indicate the insertion lies within the two flanking restriction sites. Arrows above each map and the corresponding numbers indicate the sizes of fragments obtained for SstI digests of genomic DNAs from each allele.

in the control of both vegetative and reproductive lateral organ identity in plants.

\section{Results}

Molecular cloning of Glossy15

A mutable allele of Gl15 (g115-m1) was isolated previ- ously and determined by genetic tests to be induced by a $d S p m$ transposable element insertion (Moose and Sisco 1994). The $d S p m$ element fragment BX-1 (Cone et al. 1986) was used as a hybridization probe in DNA gel-blot analyses of families segregating for $g 115-\mathrm{m} 1$. We identified a 3.3-kb SstI fragment that cosegregated with the g115-m1 mutant phenotype. Representative homozygous and heterozygous $g 115-\mathrm{m} 1$ plants with the $3.3-\mathrm{kb} S p m$ hybridizing fragment are shown in Figure $2 \mathrm{~A}$ (lanes $\mathrm{M}$ and $\mathrm{M} / \mathrm{H}$. Convincing evidence that the $3.3-\mathrm{kb}$ SstI fragment represented a $d S p m$ insertion in the Gl15 gene came from the absence of this fragment in DNA from plants homozygous for germinal revertant alleles derived from g115-m1 (Fig. 2A, lane R). No other Spm-hybridizing fragments from $g 115-\mathrm{m} 1$ plants were found to be missing consistently from these derivatives.

A size-fractionated subgenomic library of SstI fragments from homozygous g115-m1 plants was constructed and the 3.3-kb SstI fragment isolated using the $B X-1$ probe. Figure $2 B$ shows the restriction map of the cloned 3.3-kb SstI fragment, which contained a $2.1-\mathrm{kb}$ $d S p m$ element insertion flanked by non-Spm sequences. A restriction fragment containing only non-Spm flanking DNA (HS1 100.43) was used as a hybridization probe to the same DNA gel blot shown in Figure 2A. This blot contained DNAs representative of normal G115 (inbred W64A) and three previously identified g115-Ref mutant alleles (Moose and Sisco 1994) in addition to g115-m1, a derivative revertant allele, and one of its mutant siblings. The resulting hybridization pattern is shown in Figure 2C. Homozygous g115-m1 plants, which exhibit an unstable phenotype in the presence of autonomous Spm, showed the expected 3.3-kb SstI fragment and a low-intensity $1.2-\mathrm{kb}$ fragment (lane M). The $1.2 \mathrm{~kb}$ fragment was correlated with the generation of somatic revertant sectors from gl15-m1 and thus represented the original progenitor allele. Proof that the HS1 100.43 fragment represented part of the Gl15 gene came from comparing a germinal revertant derivative of $g 115-m 1$ (lane $\mathrm{R}$ ) with its mutable sibling (lane $\mathrm{M} / \mathrm{H}$ ). The homozygous revertant plant contained only a $1.2-\mathrm{kb}$ SstI hybridizing fragment, whereas its mutable sibling, heterozygous for the g115-m1 and Hayes alleles, contained 3.3-kb $(\mathrm{M})$ and 1.6-kb $(\mathrm{H})$ fragments. The size difference between the restriction fragments representing $g 115-\mathrm{m} 1$ and either its somatic or germinal revertant derivatives was consistent with the $2.1-\mathrm{kb} d S p m$ insertion observed within the cloned 3.3-kb SstI fragment (Fig. 2B). The 1.2-kb SstI fragment was present in all 15 maize inbreds tested that carried normal Gl15 alleles, such as the inbred W64A (Fig. 2C, lane W). In contrast, each of the three g115Ref(erence) alleles-g115-H(ayes), gl15-L(ambert), and g115-S(prague) - were associated with other fragment sizes (lanes $\mathrm{H}, \mathrm{L}$, and $\mathrm{S}$ ).

The HS1 100.43 fragment was used as a probe to isolate wild-type Gl15 cDNA and genomic clones from the inbred W64A. Restriction mapping and DNA sequencing of these clones indicated that a 6.0-kb EcoRI genomic fragment contained the entire Gl15 transcribed region, as shown in Figure 3A. To determine where the lesions 


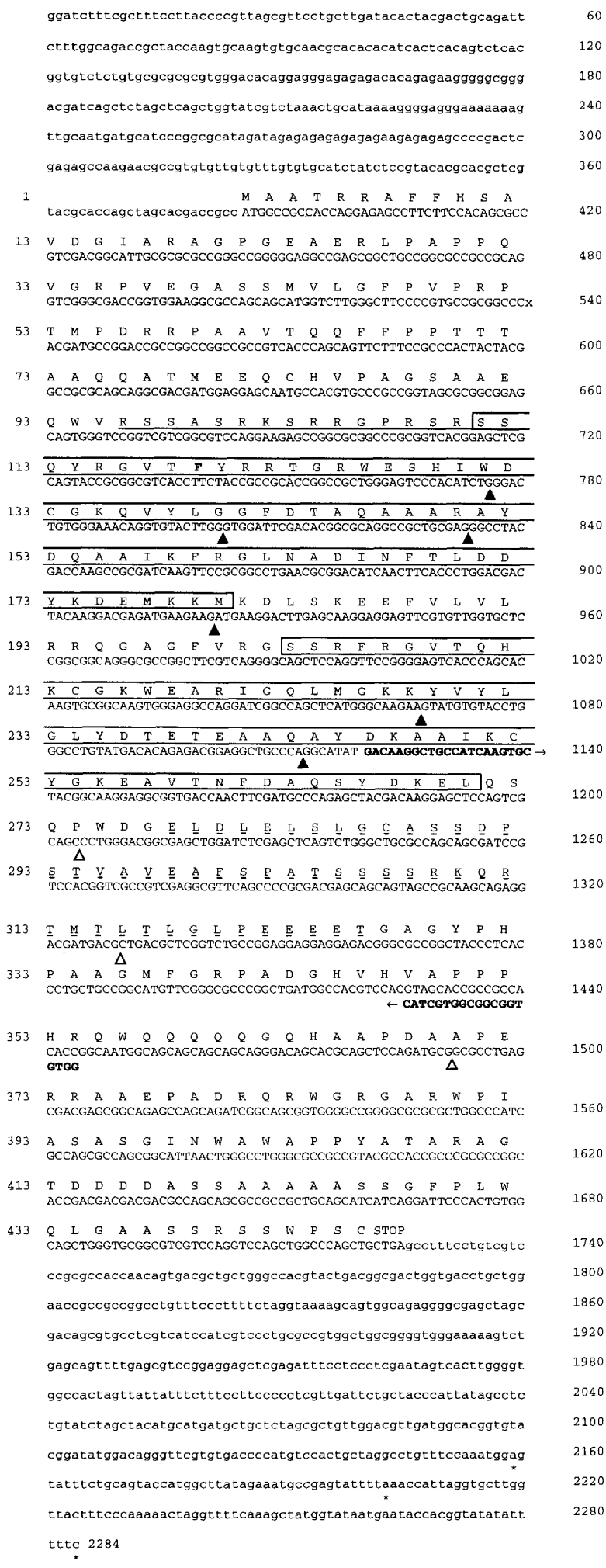

responsible for the other three known g115 mutations were located, DNA gel blots were prepared from plants homozygous for these alleles and hybridized sequentially to the P700.G1, HS1 100.43, and S980.G6 probes. Analysis with multiple restriction enzymes demon-
Figure 4. Sequence of the G115 cDNA. The nucleotide sequence of the Gl15 gene and the predicted amino-acid sequence of its corresponding protein are shown. Amino-acid numbers are given on the left and nucleotides are numbered on the right of the sequence. Boxed amino acids represent the two AP2 domains (Jofuku et al. 1994). The solid underlined residues indicate the basic region with potential nuclear-localization activity (Varagona et al. 1992), and the dashed underlined residues represent a serine-rich acidic domain. The six intron positions conserved between G115 and AP2 are marked by filled arrowheads, and open arrowheads show the positions of other introns. Asterisks denote the three observed polyadenylation sites. The phenylalanine (F) residue in bold indicates the position of the $d S p m$ insertion in $g 115-m 1$. Nucleotides in bold represent the sequences of the G115 primers used in RT-PCR.

strated that each g115-Ref allele exhibited either large insertions or deletions within the $1.2 \mathrm{~kb}$ Sst I fragment observed in wild-type alleles. The approximate sizes and locations of these lesions appear in Figure 3B. The gl15- $H$ allele was characterized by a 1100 -bp deletion that removed the entire $5^{\prime}$ end of the G115 mRNA. The g115- $L$ allele contained a 500-bp insertion and the g115-S allele a 1600-bp insertion with internal SstI, BglII, HindIII, $E c o R V$, and EcoRI restriction sites. The nature of the insertions in the g115- $L$ and g115-S alleles is currently unknown. An additional RFLP was identified in the g115- $L$ allele by the lack of one of the sites defining the 1500-bp SstI fragment in the G115-W64A allele. This same site may also be only partially cleaved in the g115- $H$ allele, which would account for the two hybridizing fragments of $1.6-\mathrm{kb}$ and $1.9-\mathrm{kb}$ when HS1100.43 was used as a probe (Fig. $2 \mathrm{C}$ ).

\section{Gl15 encodes an AP2-domain protein}

Figure 4 shows the complete nucleotide and predicted amino acid sequence of the longest (2284-bp) Gl15 cDNA. Two unspliced introns, two differentially spliced introns, and three alternative polyadenylation sites were observed among the three Gl15 cDNA clones that we sequenced. Variation in intron splicing is commonly observed in plant cDNA sequences (Nash and Walbot 1992). The longest (1341-bp) open reading frame encoded a 446-amino-acid polypeptide with a predicted molecular mass of $48 \mathrm{kD}$. Translation of the cDNA sequence upstream of the ATG start codon shown in Figure 4 revealed two short (five- to seven-amino-acid) open reading frames beginning at positions 246 and 249 .

Data-base comparisons showed that the central portion of the predicted G115 protein was very similar to the AP2 domain, a conserved motif first identified in the Arabidopsis floral homeotic gene AP2, but also found within a number of genes from Arabidopsis, rice, and other taxonomically diverse plant species (Jofuku et al. 1994; Weigel 1995). One of these proteins, EREBP-2, has been reported to possess sequence-specific DNA-binding activity, with the AP2 domain being essential for this activity (Ohme-Takagi and Shinshi 1995). Figure 5 
shows the two AP2 domains from Gl15 aligned with those of other genes present in sequence data bases. When compared with these other sequences, G115 was most similar to AP2. Over a 170 -amino-acid conserved region, Gl15 and $A P 2$ shared $80 \%$ amino-acid identity. This conserved region spanned the two repeated AP2 domains, the linker region between the domains (Klucher et al. 1996) and a basic region representing a putative nuclear localization signal (Varagona et al. 1992). Additionally, within the AP2 domains, the positions of six introns were conserved exactly between $A P 2$ and $G 115$ (Fig. 4). Outside of the AP2 domains and the basic region, G115 did not share any significant similarities in primary amino acid sequence with other genes. Like $A P 2$ and $A N T, G 115$ has a serine-rich acidic domain (amino acids 278-326) and a histidine/glutamine-rich region (residues 345-364) that may serve as transcription activation domains (Mitchell and Tjian 1989; Jofuku et al. 1994). However, in the $A P 2$ and $A N T$ proteins, these putative transcription activation domains are in the amino-terminal region, whereas in Gl15 they reside on the carboxyterminal side.

The insertions or deletions associated with each of the characterized gl15 mutant alleles were localized to the region encoding the conserved AP2 domains (Figs. $2 \mathrm{C}, 3 \mathrm{~B})$. The insertion site of the $d S p m$ transposable element in $g 115-\mathrm{m} 1$ was near the $3^{\prime}$ end of the first exon. The deletion in $8115-H$ removed portions of the putative promoter region and much of the first exon, which resulted in a transcriptional null allele (see Fig. 7A, lane $\mathrm{H}$, below). The relatively large insertions in the g115- $L$ and g115-S mutant alleles also interrupt AP2 domains. Therefore, it is unlikely that any of the characterized g115 mutant alleles produce a functional protein.

$G 115$, although very similar to $A P 2$, is probably not the
AP2 ortholog in maize. Mutations in the two genes have very different phenotypes, and maize cDNA libraries probed with $A P 2$ have identified other AP2-related genes but not G115 (G. Chuck and S. Hake, pers. comm.). At least one of these maize genes was more homologous to $A P 2$ than is Gl15. Another indication that Gl15 represents a divergent member of the AP2-domain gene family was our finding that the G115 S500.JS cDNA probe, which includes almost the entire conserved AP2 region, did not identify any hybridizing fragments in maize other than Gl15 at standard stringencies. Moreover, DNA blots probed with G115 subclones from both within and outside the conserved AP2 region revealed that sequences specifically related to G115 are present as a single copy in several grasses (sorghum, pearl millet, Andropogon virginicus, and Lolium) and in low copy number in the dicot species soybean, tobacco, Arabidopsis, and peach (data not shown).

\section{Gl15 mRNA expression is correlated with the gl15 mutant phenotype}

The P700.Gl fragment was used in gel-blot analyses of maize leaf RNAs. Figure 6 shows a $2.2-\mathrm{kb}$ G115 mRNA whose size was in agreement with that of the longest G115 cDNAs we isolated. The expression pattern of the G115 mRNA was correlated with the G115 phenotype. The G115 mRNA was present as a low-abundance transcript in poly $(\mathrm{A})^{+}$RNA from juvenile leaves 4-6. Hybridization to the P700.Gl probe was also detectable, but greatly reduced, in mRNA from leaves 1 and 2, whose juvenile phenotypes are not affected by g115 mutations. Because adult epidermal cell types are observed occasionally at the base of leaf 2 in g115 mutant plants (Evans



Figure 5. Sequence comparison of AP2 domains from Glossy15 and other AP2 domain genes. Shown are the AP2 domain amino-acid sequences from the deduced cDNAs of Glossy15 (accession no. U41466), Arabidopsis APETALA2 (ATU12546; Jofuku et al. 1994), a rice EST (D23002), Arabidopsis AINTEGUMENTA (U40256; Klucher et al. 1996), a maize ORF sequence (Z47554, ZMMHCF1), the tobacco ethylene-response element DNA-binding protein EREBP-2 (D38126; Ohme-Takagi and Shinshi 1995), and the Arabidopsis TINY gene (X94698, Wilson et al. 1996). The amino acids of the two AP2 domains (as defined in Jofuku et al. 1994) are indicated above the sequences, and the putative nuclear localization signal sequences are underlined. Asterisks represent amino acids identical to Glossy15; gaps included to optimize alignment are indicated by periods. The number at the beginning of each sequence is the number of amino-acid residues from the first methionine or the first amino acid of the reading frame. The single AP2 domain in EREBP-2 displayed similar degrees of identity $(38 \%)$ when aligned to either of the two AP2 domains from Glossy15. 


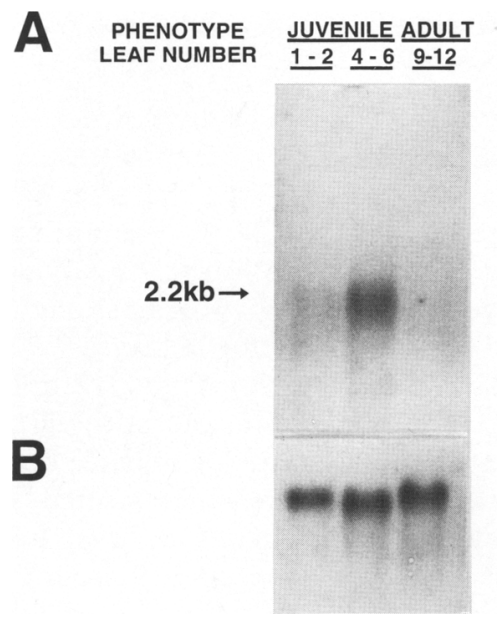

Figure 6. RNA gel-blot analysis of poly $\mid \mathrm{A})^{+}$RNA isolated from maize leaves. Ten micrograms of poly $(\mathrm{A})^{+}$RNA from W64A leaves 1 and 2 (juvenile phenotype), leaves 4-6 (juvenile phenotype), and leaves 9-12 (adult phenotype) were loaded per lane. Each RNA sample included only developing unexpanded leaf tissue within $10 \mathrm{~cm}$ of, but excluding, the shoot apex. $(A)$ The blot was hybridized to the P700.G1 G115 probe, which detected a $2.2-\mathrm{kb}$ transcript from juvenile but not adult leaf mRNA. $(B)$ The blot in $A$ was stripped and rehybridized with a maize actin probe (Shah et al. 1983) as a control for RNA loading.

et al. 1994; Moose and Sisco 1994), Gl15 may control the differentiation of a small proportion of basal epidermal cells within leaf 2 and thus account for the hybridization signal in leaves 1 and 2. It is also possible that there is another Gl15-related gene that controls the juvenile identity of the first two leaves, to which the P700.G1 probe may hybridize weakly. The G115 transcript was not detected in adult leaf mRNA, consistent with our other observations that Gl15 activity is correlated strictly with the juvenile epidermal phenotype beyond leaf 2.

Because of the low abundance of the Gl15 transcript even in leaves 4-6, we exploited the sensitivity of reverse transcription-PCR (RT-PCR; Byrne et al. 1988) to further characterize Gl15 expression during maize development. Figure 7 shows the results from one such RTPCR experiment. Among leaves from normal plants, G115 mRNA expression was observed as expected from leaves $4-6$ but was not detected in either leaves 1 and 2 or adult leaves. These results, when compared with those in Figure 6, suggested that the hybridization signal obtained from leaves 1 and 2 in RNA gel-blot analysis may represent cross-hybridization with a putative Gl15related gene that is expressed in early juvenile leaves. Very low levels of a Gl15-related RT-PCR product were detected in the plumule, or embryonic leaves, harvested from late-stage ( 32 days after pollination) developing embryos. Because the plumule contains the first 5-6 leaf primordia (Kiesselbach 1949; Abbe and Stein 1954), we could not determine whether the observed RT-PCR product represents only Gl15 expression in leaves 3-6 or also includes the expression of a Gl15-related gene active in leaves 1 and 2.

Gl15 expression in mutant plants is also illustrated in Figure 7. No Gl15 mRNA was detected in leaves 4-6 from the g115- $H$ deletion mutation, demonstrating that it is a null allele. Gl15 transcripts were detected in mRNA isolated from leaves 14-16 of Cg1 mutant plants, whereas in normal plants leaves of the same developmental age (leaves 9-12) exhibit an adult epidermal cell identity and do not express G115 (Figs. 6,7). The ectopic expression of Gl15 mRNA beyond leaf 8 in Cg1 mutant plants is consistent with the genetic observations that G115 is required for the near-constitutive expression of juvenile epidermal cell traits conditioned by $C g 1$ and that it acts downstream of the $C g 1$ mutation (Moose and Sisco 1994).

The RT-PCR analysis was not quantitative as performed. Thus differences in intensities of signals among samples in Figure 7 do not necessarily reflect the relative abundance of Gl15 transcript present in the RNA sample. Successful reverse transcription was verified for each sample through the amplification of a 700-bp product from the maize $b-70$ mRNA encoding the endoplasmic reticulum-localized molecular chaperone $\mathrm{BiP}$ (Fontes et al. 1991; see Materials and Methods). The results obtained from both RNA gel blots and RT-PCR are consistent with the presence of a distinct middle domain within the normal maize shoot (leaves 3-7 in the inbred W64A) and indicate that after leaf 2 , a juvenile leaf identity requires the expression of the Gl15 gene.

\section{Discussion}

Glossy15 is the first molecularly characterized gene that regulates the transition from juvenile to adult shoot de-

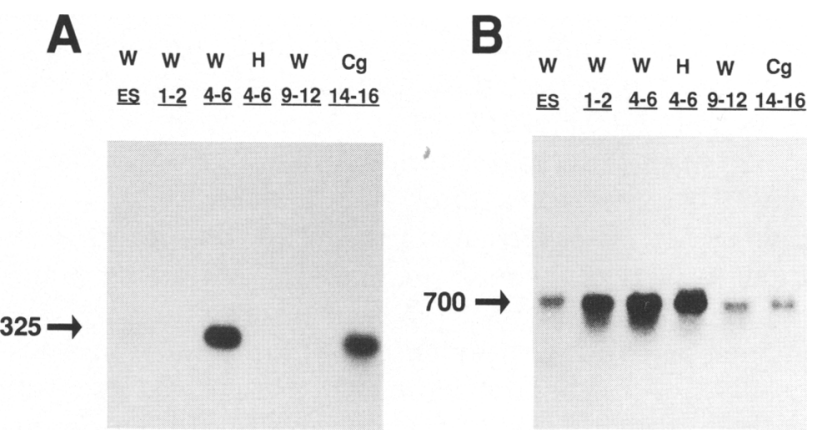

Figure 7. RT-PCR analysis of maize G115 mRNA expression. First-strand cDNAs from W64A embryonic shoots, W64A leaves 1 and 2, W64A leaves 4-6, g115- $H$ leaves 4-6, W64A leaves 9-12, and $\mathrm{Cg} 1 /+$ leaves $14-16$ were amplified by PCR, resolved by agarose gel electrophoresis, blotted onto a nylon membrane, and hybridized to labeled probes as described in the Materials and Methods. (A) PCR amplification with the G115specific primers shown in Fig. 4 and probed with the SP430.JS probe from G115. The arrow indicates the 325-bp product detected by the $G 115$ probe. $(B)$ PCR amplification with primers from the $b-70$ gene and probed with the entire $b-70 \mathrm{cDNA}$. The arrow indicates the $700-\mathrm{bp}$ product detected by the $b-70$ probe. 
velopment in plants. The correlation of distinct RFLPs with the g115-m1 allele, its revertant derivatives, and the three gl15-Ref mutations served as evidence that the DNA flanking the $d S p m$ insertion in $g 115-m 1$ represented a portion of the G115 gene. Our characterization of Gl15 mRNA expression, its predicted protein sequence, and comparisons to other related genes indicated that leaf epidermal cell identity in maize is determined by this AP2-domain transcription factor. This finding expands the known functions of $A P 2$-related genes and suggests that similar genes in other plants may participate in the determination of vegetative as well as reproductive lateral organ identity.

\section{The Gl15 protein has features of transcription factors}

The Gl15 protein shares a number of similarities to known transcription factors. Gl15 contains two repeated AP2 domains that both share identity with all 24 of the AP2 domain consensus residues as determined by Weigel (1995). The AP2 domain is a novel motif that is predicted to form an amphipathic $\alpha$-helix and, in both $A P 2$ and Gl15, is flanked by a 10 -amino-acid basic region proposed to function as a nuclear localization signal (Jofuku et al. 1994). Regions capable of forming an $\alpha$-helical structure and having a high density of basic amino acids are consistent with a DNA-binding motif (Mitchell and Tiian 1989). The ability to form amphipathic $\alpha$-helices suggests that the core region of the AP2 domain may mediate protein-protein interactions, possibly as a dimerization domain with other related proteins (Cohen and Parry 1994; Jofuku et al. 1994). The presence of two AP2 domains within G115 may permit DNA binding by a single polypeptide, whereas genes with only a single AP2 domain, such as EREBP-2 from tobacco, may require the formation of homo- or heterodimers for DNA binding activity. Additionally, G115 has a serine-rich acidic region and a histidine/glutamine stretch (Fig. 4) that may serve as transcription activation domains (Mitchell and Tjian 1989).

A transcription factor function for G115 is consistent with the pleiotropic effects of g115 mutations on a diverse set of epidermal traits and its cell-autonomous mode of action. Phenotypic analysis of g115-m1 plants demonstrated that $G 115$ both activates juvenile and suppresses adult leaf epidermal traits (Moose and Sisco 1994). Potential downstream targets of G115 activity include genes involved in epicuticular wax biosynthesis, cell-wall metabolism, and cellular differentiation pathways. Interestingly, increased or ectopic expression of the Arabidopsis TINY gene, which encodes a protein with a single AP2 domain, conditions changes from an irregular to a rounded leaf epidermal cell shape (Wilson et al. 1996). Gl15 activity also induces similar effects in the maize leaf epidermis. Nevertheless, the amino acid sequence of the TINY protein is significantly different from that of the double-AP2-domain proteins (Fig. 4), and TINY is clearly not the Arabidopsis ortholog of Gl15.
Gl15 and the regulation of vegetative phase change in maize

Shoot growth in maize can be divided into distinct juvenile and adult phases, which differ by the expression of a large set of traits, including the character of the leaf epidermis. Previous analysis of g115 mutations indicated the juvenile phase may be further subdivided into two separate juvenile regulatory programs, one operating in leaves 1 and 2, the other acting in leaves 3-7 (Evans et al. 1994; Moose and Sisco 1994). The G115 mRNA expression pattern in normal plants and in the g115- $H$ null allele demonstrated the existence of three developmental domains within the shoot, each associated with distinct leaf epidermal cell identities. The basal 1-3 leaves are juvenile but regulated independently from Gl15; middle leaves have a juvenile identity that is promoted by G115; and upper leaves are adult. The replacement of juvenile with adult epidermal cell phenotypes in the middle leaves of g115 mutants suggests that G115 suppresses adult epidermal cell differentiation and that the absence of G115 activity conditions an adult epidermal cell fate. However, if Gl15 does antagonize the activity of adult genes, then it must do so only in leaves 3-7, because upper leaves of $C g 1$ plants possess both juvenile and adult epidermal cell types (Moose and Sisco 1994) but continue to express Gl15 mRNA (Fig. 7).

The expression of G115 itself appears to respond to the activity of factors that affect phase change globally, such as those defined by the $C g 1$ and $T p$ mutations or possibly the gibberellin class of plant growth regulators (Evans and Poethig 1995). However, nothing is known at the molecular level about the upstream regulators of Gl15 expression or their mechanism of action. Molecular and genetic studies in Arabidopsis have demonstrated that $A P 2$, in conjunction with other factors, negatively regulates the expression of the MADS-box gene AGAMOUS $(A G)$ in the outer two whorls of the Arabidopsis flower, resulting in the formation of perianth (sepals and petals) rather than sexual organs (Drews et al. 1991; Jofuku et al. 1994). Further work suggests that AP2 cooperates with both LEUNIG (Liu and Meyerowitz 1995) and the MADS-box gene APETALA1 (Irish and Sussex 1990) to mediate its effects on floral meristem and organ identity. Thus G115 may interact with similar genes to regulate leaf identity in maize. Though most characterized MADS-box genes are expressed in developing flowers, vegetatively expressed MADS-box genes have been identified in a number of plant species, including maize (Pnueli et al. 1991; Mandel et al. 1994; Mena et al. 1995; Rounsley et al. 1995; Tandre et al. 1995). The isolation and characterization of loss-of-function mutations in these genes may reveal their role in regulating vegetative meristem or leaf identity.

\section{AP2-related genes regulate both vegetative and floral organ identity in plants}

A large number of genes have been identified that contain an AP2 domain (Weigel 1995). Among these genes, 
only those of a relatively small subset possess two repeated AP2 domains. The presence of sequences related specifically to either GI15, AP2, or ANT in both monocot and dicot species (Fig. 5 and data not shown) suggests that each of these three genes is descended from a common ancestral gene that underwent subsequent diversification during plant evolution. This diversification is reflected in the observed differences among G115, AP2, and $A N T$ with respect to their mutant phenotypes, AP2domain sequences, and expression patterns during plant development. The AP2 and ANT genes are expressed in both vegetative and floral tissues, but exhibit a mutant phenotype only during reproductive development (Jofuku et al. 1994; Elliott et al. 1996; Klucher et al. 1996). This is in contrast to G115, whose mRNA expression pattern is correlated with the g115 mutant phenotype in juvenile vegetative leaves (Figs. 6 and 7). The possibility exists that $A P 2$ and $A N T$ also function during vegetative development, but redundant gene activities prevent the observation of a vegetative phenotype in ap2 or ant mutants. Genetic redundancy for Gl15 activity may also account for the continued juvenile character of the first two leaves in g115 mutations (Evans et al. 1994; Moose and Sisco 1994).

If $G 115, A P 2$, and $A N T$ are derived from a common ancestral gene, then to what extent have the functions of these genes been conserved? Mutations in AP2 affect $A r$ abidopsis floral meristem and floral organ identity, ovule formation, or the development of the seed coat, which is derived from the integuments in the ovule (Jofuku et al. 1994). ANT mutants affect mainly the initiation of lateral organs (the integuments) in the ovule, but also alter organ number and morphology in the outer three whorls of the flower (Elliott et al. 1996; Klucher et al. 1996). Gl15 is required for a juvenile leaf epidermal cell identity during maize shoot development. Thus, each of these genes influence the formation of lateral organs (leaves, floral organs, or integuments) derived from developing meristems. Important differences exist, however, in where these $A P 2$-related genes regulate this process. AP2 regulates both floral meristem and floral organ identity, and therefore acts throughout reproductive development. ANT appears to have a general role in the initiation of lateral organs from both shoot and floral meristems. In contrast, the limited phenotypes and mRNA expression patterns of G115 indicate that it functions specifically to control leaf epidermal cell identity.

The finding that $A P 2$-related genes regulate lateral organ identity during both vegetative and reproductive development supports the hypothesis that leaves and floral organs are related structures derived from a common growth plan (Goethe 1790; Coen and Carpenter 1993). The presence of G115-related sequences in taxonomically diverse plant species suggests that similar genes may also regulate leaf identity in other heteroblastic plants. The continued characterization of G115 and other maize genes that regulate its activity, such as $C g 1, T p 1$, and $T p 2$, should provide additional insights into the control of vegetative phase change and leaf identity in plants.

\section{Materials and methods}

Genetic stocks

The origin, identification, and genetic characterization of the g115-m1::dSpm allele were described previously in Moose and Sisco (1994). The $g 115-H$ and g115-S stocks were obtained from the Maize Genetics Cooperation Stock Center (Urbana, IL), and the g115-L stock from G.F. Sprague /United States Department of Agriculture/Agricultural Research Service, retired, Eugene, OR). Each of these mutations and a $C g 1 /+$ mutant obtained from R. Bertrand (Colorado College, Colorado Springs) had been backcrossed three times into the W64A inbred background. Revertant alleles $\left(G 115^{\prime}+\right)$ derived from g115-m1::dSpm were identified in plants exhibiting a heritable normal juvenile seedling phenotype and a $W_{X} / w_{X}$ genotype among $F_{1}$ progeny from the cross $g 115-m 1, W_{x}, S p m \times g 115-H, w x$. The kernel mutant waxy (wx), $10 \mathrm{cM}$ from g115 (Coe 1993), was used as a genetic marker to control against wild-type $\{G 115\}$ pollen contamination. Candidate revertants were selfed, and progeny homozygous for the G115' alleles were selected. Crosses were performed by hand pollination either in a greenhouse or at a Clayton, NC, summer nursery.

\section{DNA methods}

The BX-1 Spm element probe was obtained from R. Schmidt (University of California at San Diego). Maize inbred W64A plants were grown from seed in a greenhouse and its genomic DNA was isolated by a CTAB procedure as described in SaghaiMaroof et al. (1984). DNA gel blots were prepared and hybridized to gel-purified, random primer radioactively labeled DNA fragments according to Sisco (1991), except $100 \mu \mathrm{g} / \mathrm{ml}$ herring sperm DNA and $5 \times$ Denhardt's solution $15 \times$ is $0.1 \% \mathrm{wt} / \mathrm{vol}$ Ficoll, $0.1 \% \mathrm{wt} / \mathrm{vol} \mathrm{BSA}, 0.1 \% \mathrm{wt} / \mathrm{vol}$ polyvinylpyrollidone) were used instead of heparin. The hybridization temperature for the $\mathrm{BX}-1$ probe was $75^{\circ} \mathrm{C}$. All other hybridizations were carried out at $68^{\circ} \mathrm{C}$. Filters were washed once for $20 \mathrm{~min}$ in $2 \times \mathrm{SSC}$, $0.15 \mathrm{M} \mathrm{NaCl}, 0.015 \mathrm{M}$ sodium citrate, $0.1 \%$ SDS at $65^{\circ} \mathrm{C}$, twice for $20 \mathrm{~min}$ in $1 \times \mathrm{SSC}, 0.1 \% \mathrm{SDS}$ at $65^{\circ} \mathrm{C}$, and twice for $10 \mathrm{~min}$ in $0.1 \times$ SSC, $0.1 \%$ SDS at $65^{\circ} \mathrm{C}$. Filters were autoradiographed at $-80^{\circ} \mathrm{C}$ from 1 to 14 days.

\section{Genomic cloning}

DNA used in molecular cloning was prepared by a CTAB procedure (Saghai-Maroof et al. 1984). To obtain the 3.3-kb SstI fragment representing $g 115-m 1:: d S p m$, a partial genomic DNA library was prepared from total genomic DNA of homozygous g115-m1 plants by size-selection and purification (GeneClean, BIO 101) of 3-4 kb SstI fragments through an agarose gel. The purified fragments were ligated to SstI-EcoRI linkers and cloned into dephosphorylated, EcoRI-digested $\lambda$ Zap (Stratagene). Packaging into Gigapack Gold (Stratagene), plating on either SURE or XL1-Blue MRF host strains, and screening of this and subsequent libraries was carried out according to the manufacturer's protocols. Three BX-1 hybridizing clones were obtained from $\sim 1 \times 10^{6}$ plaques and converted to pBluescript phagemids by the recommended in vivo excision protocol (Stratagene). One plasmid possessed a $3.3-\mathrm{kb}$ SstI insert with an internal $2.1-\mathrm{kb}$ $d S p m$ element flanked by maize genomic sequences. A $1.1-\mathrm{kb}$ HindIII-SstI fragment (HS1 100.43, Fig. 2) was isolated from this clone and used in subsequent analyses.

Genomic clones for the G115-W64A allele were obtained from a total W64A genomic DNA library. Total genomic DNA was partially digested with Sau3AI, and partially filled in with dATP and dGTP. Fragments from $9 \mathrm{~kb}$ to $25 \mathrm{~kb}$ were selected and 
purified from agarose gels (Weil and Bureau 1994). Prepared fragments were subsequently ligated to the $\lambda$ FixII vector (Stratagene), packaged, and $\sim 1 \times 10^{6}$ recombinant clones screened with the HS1100.43 probe. Eleven hybridizing clones were isolated, nine of which represented overlapping clones from the G115 locus. The 6.0-kb EcoRI fragment from one of these clones (G6) that hybridized to HS1100.43 was subcloned into pBluescript KS + (Stratagene).

\section{cDNA cloning and sequence analysis}

Total RNAs from W64A shoots harvested at 3, 6, 9, and 13 days after kernel sowing (DAS) were isolated using a protocol modified from Chirgwin (1979; M. Redinbaugh, pers. comm.). The 9 DAS and 12 DAS samples included only young developing leaves 4-6 and the shoot apex. Equal amounts of RNA (by weight) from each time point were pooled together. This pooled sample was intended to represent all possible developmental stages of both early juvenile and late juvenile leaves. Poly $|\mathrm{A}|^{+}$ RNA was selected by passage through oligo|dT) cellulose columns (Clonetech) and $\sim 5 \mu \mathrm{g}$ of juvenile shoot mRNA was used to construct a cDNA library with the ZAP-cDNA Synthesis Kit (Stratagene) according to the manufacturer's instructions. Six G115 cDNA clones were identified by screening $5 \times 10^{5}$ primary recombinant plaques with the P700.Gl probe. These were converted to pBluescript phagemids by in vivo excision and determined to carry insert lengths from $1.8 \mathrm{~kb}$ to $2.3 \mathrm{~kb}$. Portions of each of these clones were subcloned into pBluescript vectors.

Subclones from the $8115-\mathrm{m} 1$ genomic clone, the $6.0-\mathrm{kb}$ EcoRI G115-W64A genomic clone, and W64A G115 cDNA clones were prepared by use of standard techniques. Both strands from these clones were sequenced using standard Sequenase (U. S. Biochemical) protocols or through the Applied Biosystems (Foster City, CA) sequencers at Iowa State University, Ames. DNA sequence analysis was performed using the programs (version 8 ) of the Wisconsin Genetics Computer Group (Madison, WI), and data-base searches were conducted using the BLAST network service at the National Center for Biotechnology Information at the National Library of Medicine (Bethesda, MD).

\section{RNA analysis}

Total RNAs were isolated (as above) from greenhouse-grown W64A plants at the following developmental stages: leaves 1 and 2 at 6 days after sowing (DAS), leaves $4-6$ at 12 DAS, and leaves 9-12 at 33 DAS. Each sample included both developing and fully differentiated leaf tissue. Poly $(\mathrm{A})^{+}$RNA was selected by passage through oligo(dT) spin columns (Clontech). mRNAs $(10 \mu \mathrm{g})$ were electrophoresed through a $1.3 \%$ formaldehyde gel and transferred to GeneScreen + membrane (DuPont) in $0.05 \mathrm{M}$ $\mathrm{NaOH}$ for $6 \mathrm{hr}$. Hybridizations and washes were conducted as for high-stringency genomic DNA blots with the membrane sandwiched between two pieces of 3MM Whatman filter paper (Jones and Jones 1992).

Total RNAs from the above W64A leaf samples, developing W64A embryonic axes dissected from kernels at 35 days after pollination, leaves 4-6 of homozygous g115- $H$ plants at 12 DAS, and leaves $14-16$ of heterozygous $C g 1 /+$ plants at 33 DAS were used to amplify the Gl15 transcript by RT-PCR. The g115- $H$ and Cg1 mutant alleles had been backcrossed three times into a W64A inbred background. First-strand cDNA was synthesized using $5 \mu \mathrm{g}$ of total RNA at $48^{\circ} \mathrm{C}$ for $1 \mathrm{hr}$ using oligo(dT) $(n=15)$ and SuperScriptII modified reverse transcriptase (Bethesda Research Laboratories/ as described by the manufacturer. PCR was performed on $2 \mu \mathrm{l}$ of the first-strand cDNA reaction in a final volume of $100 \mu \mathrm{l}$, using either the Gl15-specific primers shown in Figure 3 or the following primers from the maize $b-70$ gene (GenBank accession no. M59449): 5'-CCTGCGACTTCTTGGTCGGGAT-3' and 5'-CTTGTCTTTGACCTTGGTGGTG$3^{\prime}$. The reactions were initially denatured at $97^{\circ} \mathrm{C}$ for $3 \mathrm{~min}$, followed by 3 cycles of $97^{\circ} \mathrm{C}$ for $1 \mathrm{~min}, 55^{\circ} \mathrm{C}$ for $1 \mathrm{~min}$, and $72^{\circ} \mathrm{C}$ for $1 \mathrm{~min}$. Thirty-five additional cycles were conducted at $94^{\circ} \mathrm{C}$ for $1 \mathrm{~min}, 55^{\circ} \mathrm{C}$ for $1 \mathrm{~min}$, and $72^{\circ} \mathrm{C}$ for $90 \mathrm{sec}$. Thirty microliters from each PCR was electrophoresed through agarose gels, blotted to nylon membrane, and hybridized to either Gl15 or $b-70$ probes as described above.

\section{Acknowledgments}

We thank Russell Wrobel, Ralph Dewey, John Goode, Lynn Senior, and William Thompson for helpful advice regarding DNA gel blots, library construction, and DNA sequencing. We are grateful to Christian Kermorvant and Nichole Sprouse for their assistance with gel blots and DNA sequencing, William G. Brown, Ir., for excellent care of greenhouse and nursery plants, and Wilma $\mathrm{Hu}$ for the photography of figures and help with scanning electron microscopy. We thank Rebecca Boston and R. Wrobel for the maize $b-70$ gene primers, Robert Schmidt for the BX-1 Spm probe, and the laboratories of Sarah Hake, Robert Fischer, and David Smyth for communicating unpublished data. Michael Lee, Michael Purugganan, Ralph Dewey, and Ross Whetten supplied genomic DNAs used in the cross-species analysis. This work was supported by USDA/ARS CWU 664521000-006-00D and USDA-National Research Initiative Competitive Grant 93-37304-8916 to P.H.S. S.P.M. was supported by a Plant Molecular Biology Fellowship from the North Carolina Biotechnology Center, Research Triangle Park.

The publication costs of this article were defrayed in part by payment of page charges. This article must therefore be hereby marked "advertisement" in accordance with 18 USC section 1734 solely to indicate this fact.

\section{Note}

The sequence data described in this paper for G115 cDNA have been submitted to GenBank under accession no. U41466.

\section{References}

Abbe, E.C. and O.L. Stein. 1954. The growth of the shoot apex in maize: Embryogeny. Am. J. Bot. 41: 285-293.

Allsopp, A. 1967. Heteroblastic development in plants. In $A d-$ vances in morphogenesis (ed. M. Abercrombie and J. Brachet), pp. 127-171. Academic Press, New York, NY.

Byrne, B.C., J. Li, J. Sninsky, and B.J. Poiesz. 1988. Detection of HIV-1 RNA sequences by in vitro DNA amplification. $\mathrm{Nu}$ cleic Acids Res. 16: 4165.

Chirgwin, J.J., A.E. Przbyla, R.J. MacDonald, and W.J. Rutter. 1979. Isolation of biologically active ribonucleic acid from sources enriched in ribonuclease. Biochemistry 18: 5294 5299.

Coe, E.H., Jr. 1993. Gene list and working maps. Maize Genet. Coop. News Lett. 67: 165.

Coen, E.S. and R. Carpenter. 1993. The metamorphosis of flowers. Plant Cell 5: 1175-1181.

Cohen, C. and D.A.D. Parry. 1994. $\alpha$-helical coiled-coils: More facts and better predictions. Science 263: 488-489.

Cone, K.C., F.A. Burr, and B. Burr. 1986. Molecular analysis of the maize anthocyanin regulatory locus C1. Proc. Nat1. Acad. Sci. 83: 9631-9635.

Drews, G.N., J.L. Bowman, and E.M. Meyerowitz. 1991. Nega- 
tive regulation of the Arabidopsis homeotic gene $A G A$ MOUS by the APETALA2 product. Cell 65: 991-1002.

Elliott, R.E., A.S. Betzner, E. Huttner, M.P. Oakes, W.Q.J Tucker, D. Gerentes, P. Perez, and D.R. Smyth. 1996. AINTEGUMENTA, an APETALA2-like gene of Arabidopsis with pleiotropic roles in ovule development and floral organ growth. Plant Cell 8: 155-168.

Evans, M.M.S. and R.S. Poethig. 1995. Gibberellins promote vegetative phase change and reproductive maturity in maize. Plant Physiol. 108: 475-487.

Evans, M.M.S., H.J. Passas, and R.S. Poethig. 1994. Heterochronic effects of glossy 15 mutations on epidermal cell identity in maize. Development 120: 1971-1981.

Fontes, E.B.P., B.B. Shank, R.L. Wrobel, S.P. Moose, G.R. O'Brian, E.T. Wurtzel, and R.S. Boston. 1991. Characterization of an immunoglobulin binding protein homolog in the maize floury-2 endosperm mutant. Plant Cell 3: 483-496.

Galinat, W.C. 1966. The corn grass and teopod loci involve phase change. Maize Genet. Coop. News Lett. 40: 102-103.

Goebel, K. 1900. Organography in plants. Oxford University Press, Oxford, UK.

Goethe, J.W. 1790. Versuch die Metamorphose der Pflanzen zu erklären, transl. A. Arber (1946). Chron. Bot. 10: 63-115.

Irish, V.F. and I.M. Sussex. 1990. Function of the APETALA1 gene during Arabidopsis floral development. Plant Cell 2: 741-753.

Jofuku, K.D., B.G.W. den Boer, M. Van Montagu, and J.K. Okamuro. 1994. Control of Arabidopsis flower and seed development by the homeotic gene APETALA2. Plant Cell 6: 1211-1225.

Jones, R.W. and M.J. Jones. 1992. Simplified filter paper sandwich blot provides rapid, background-free Northern blots. BioTechniques 12: 685-687.

Kiesselbach, T.A. 1949. The structure and reproduction of corn. University of Nebraska Press, Lincoln, NE.

Klucher, K., H. Chow, L. Reiser, and R.L. Fischer. 1996. The AINTEGUMENTA gene of Arabidopsis required for ovule and female gametophyte development is related to the floral homeotic gene APETALA2. Plant Cell 8: 137-153.

Lawson, E.J.R. and R.S. Poethig. 1995. Shoot development in plants: Time for a change. Trends Genet. 11: 263-268.

Liu, Z. and E.M. Meyerowitz. 1995. LEUNIG regulates AGAMOUS expression in Arabidopsis flowers. Development 121: 975-991.

Mandel, T., I. Lutziger, and C. Kuhlemeier. 1994. A ubiquitously expressed MADS-box gene from Nicotiana tabacum. Plant Mol. Biol. 25: 319-321.

Mena, M., M.A. Mandel, D.R. Lerner, M.F. Yanofsky, and R.J. Schmidt. 1995. A characterization of the MADS-box gene family in maize. Plant J. 8: 845-854.

Mitchell, P.J. and R. Tjian. 1989. Transcriptional regulation in mammalian cells by sequence-specific DNA binding proteins. Science 245: 371-378.

Moose, S.P. and P.H. Sisco. 1994. Glossy15 controls the epidermal juvenile-to-adult phase transition in maize. Plant Cell 6: $1343-1355$.

Nash, J. and V. Walbot. 1992. Bronze-2 gene expression and intron splicing patterns in cells and tissues of Zea mays $\mathrm{L}$. Plant Physiol. 100: 464-471.

Ohme-Takagi, M. and H. Shinshi. 1995. Ethylene-inducible DNA binding proteins that interact with an ethylene-responsive element. Plant Cell 7: 173-182.

Pnueli, L., M. Abu-Abeid, D. Zamir, W. Nacken, Zs. SchwarzSommer, and E. Lifschitz. 1991. The MADS box gene family in tomato: Temporal expression during floral development, conserved secondary structures and homology with ho- meotic genes from Antirrhinum and Arabidopsis. Plant $J$. 1: 255-266.

Poethig, R.S. 1988. Heterochronic mutations affecting shoot development in maize. Genetics 119: 959-973.

- 1990 . Phase change and the regulation of shoot morphogenesis in plants. Science 250: 923-930.

Rounsley, S.D., G.S. Ditta, and M.F. Yanofsky. 1995. Diverse roles for MADS box genes in Arabidopsis development. Plant Cell 7: 1259-1269.

Saghai-Maroof, M., K. Soliman, R. Jorgenson, and R. Allard. 1984. Ribosomal DNA spacer length polymorphism in barley: Mendelian inheritance, chromosomal location, and population dynamics. Proc. Natl. Acad. Sci. 81: 8014-8018.

Shah, D.M., R.C. Hightower, and R.B. Meagher. 1983. Genes encoding actin in higher plants: Intron positions are highly conserved but the coding sequences are not. I. Mol. Appl. Genet. 2: 11-26.

Sisco, P.H. 1991. Duplications complicate genetic mapping of $R f 4$, a restorer gene for cms-C cytoplasmic male sterility in corn. Crop Sci. 31: 1263-1266.

Smith, L.G. and S. Hake. 1992. The initiation and determination of leaves. Plant Cell 4: 1017-1027.

Tandre, K., V.A. Albert, A. Sundas, and P. Engstrom. 1995. Conifer homologues to genes that control floral development in angiosperms. Plant Mol. Biol. 27: 69-78.

Varagona, M. J., R.J. Schmidt, and N.V. Raikhel. 1992. Nuclear localization signal $(s)$ required for nuclear targeting of the maize regulatory protein Opaque-2. Plant Cell 4: 12131227.

Weigel, D. 1995. The APETALA2 domain is related to a novel type of DNA binding domain. Plant Cell 7: 388-389.

Weil, C. F. and T.F. Bureau. 1994. Construction of a genomic library in lambda phage. In The maize handbook (ed. M. Freeling and V. Walbot), pp. 595-598. Springer-Verlag, New York, NY.

Wilson, K., D. Long, J. Swinburne, and G. Coupland. 1996. A Dissociation insertion causes a semidominant mutation that increases expression of TINY, an Arabidopsis gene related to APETALA2. Plant Cell 8: 659-671. 


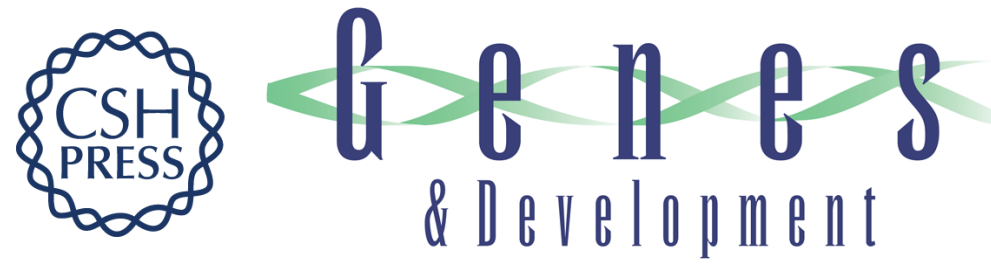

\section{Glossy15, an APETALA2-like gene from maize that regulates leaf epidermal cell identity.}

S P Moose and P H Sisco

Genes Dev. 1996, 10:

Access the most recent version at doi:10.1101/gad.10.23.3018

References This article cites 38 articles, 22 of which can be accessed free at:

http://genesdev.cshlp.org/content/10/23/3018.full.html\#ref-list-1

License

Email Alerting

Service

Receive free email alerts when new articles cite this article - sign up in the box at the top right corner of the article or click here.

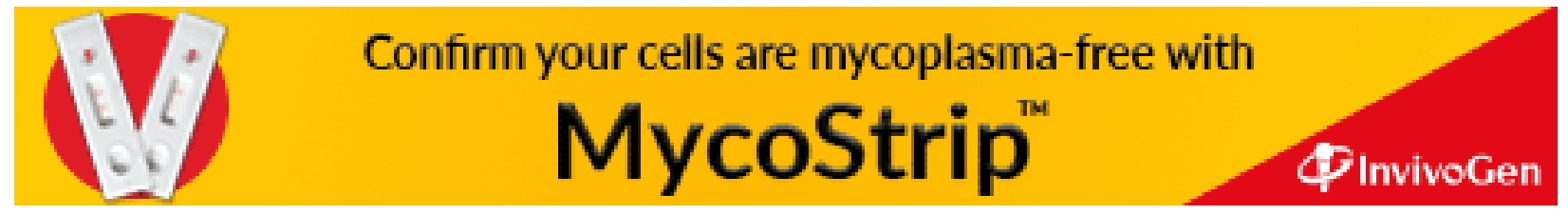

